\title{
Eosinophilic Granuloma of the Skull Treated as a Recurent Syndrom Meniere
}

\author{
Cristina Otilia Laza*1, Dan Mihail ${ }^{1}$ and Tatiana Adam² \\ ${ }^{1}$ Ent Clinic, Scju-Sf Apostol Andrei, Constanta, Romania \\ ${ }^{2}$ Hematology-Oncology Department, Scju, Constanta
}

Submission: January 15, 2018; Published: January 30, 2018

*Corresponding author: Cristina Otilia Laza, Ent Clinic, Scju-Sf Apostol Andrei, Constanta, Romania

\begin{abstract}
Eosinophilic granuloma is an uncommon granulomatous disease which can affect the temporal bone. The lesion known as a form of Langerhans cell histiocytosis is characterized by uncontrolled proliferation of Langerhans cells. Initially silent, may erode the mastoid cortex, destroy the tegmen, and extend into the cranial vault, as well as erode the semicircular canals or cochlea. These lesions almost always become infected and can be confused with chronic otomastoiditis. Equally important, temporal bone involvement may represent only one manifestation of a multifocal disease, usually the long bones are involved more often. This report describes a case of 28-year young female with eosinophilic granuloma involving the left temporal bone, treated as A Meniere vertigo with recurrent crisis in the last 3 years .Diagnosis was the results of a good imagistic and histopathology. The case was solved surgical-excision of a compact mass of granulomatous tissue occupying the mastoid process, middle and inner ear, and petrous bone without touching the tip .Diagnosis was confirm after the histopathology and IHC exams and the case was presented to the hematology, oncology department to establish the extension and for treatment cortico-therapy plus a low dose of radiotherapy-10 Gy. After 3 years no other recurrence local or at distance was observe.
\end{abstract}

Keywords: Eosinophilic granuloma; Histiocytosis X; Temporal bone; Langerhans cell; vertigo

\section{Case Report}

A 24-year-young female presented in our Clinic with a history of vertigo diagnosed and treated in neurology department as a Meniere disease with frequent recurrences since almost 3 years, progressive hearing loss in the left ear. It starts insidious but became gradually progressive. She describe also a continue dizziness, not an attack like in Meniere and also notice a progressive deafness and tinnitus more recent .From the last year she start to accuse headache ,and vomiting with release of the pain. There was no history of previous ear infection or trauma. Past medical history of the patient did not reveal any significant disease and the family history was unremarkable. There was no family history of bone diseases, skin disorders, genetic abnormalities, or endocrinopathies. She was treated in a few cases in the hospital with pev containing vasodilators and vitamins like B1,B6 ,B12, and steroids., In rest she take po when Arlevert-Cinnarizine when Betaserc-berahistine and My gamma $\mathrm{N}$ - vit B complex with no results . On physical examination, she was in a good general status, there was no mastoid tenderness, and face was symmetric. Left-sided otoscopy showed mild retraction of pars tensa. Tuning fork tests-revealed an important deafness on the left ear. Vestibular examination with Romberg test, Untenberger, Babinski, coordination test like nose-index, also was positive for a lesion of the left labyrinth. Nistagmus was positive, horizontal rotatory, the remainder of the head and neck examination was totally normal [1-5].

\section{Laboratory Test -were Normal Audiometry}

Pure Tone Audiometry: Demonstrated a moderately severe mixed hearing loss with a pure tone air conduction average of $95 \mathrm{~dB}$ hearing level (masked) and a $50 \mathrm{~dB}$ air-bone gap on his left ear.

Immitance audiometry: Type B -line-, stampeding reflex absent.

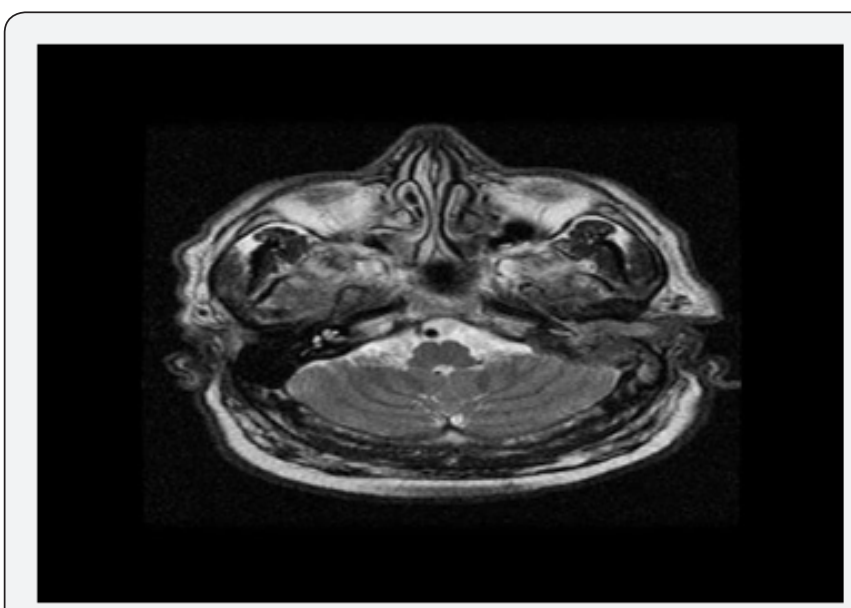

Figure 1: MRI-axial view -the cavities of inner, middle ear, mastoid process and temporal bone are filled by a solid mass with extension in the posterior cranial fossa. 
Computed Tomography: CT scan high resolution of the temporal bone revealed extensive tumoral dense mass, involving the petrous, mastoid processes with destruction of the middle and inner ear. The mass seems to be not very iodophilic so for sure wasn't glomus tympani (Figure 1).

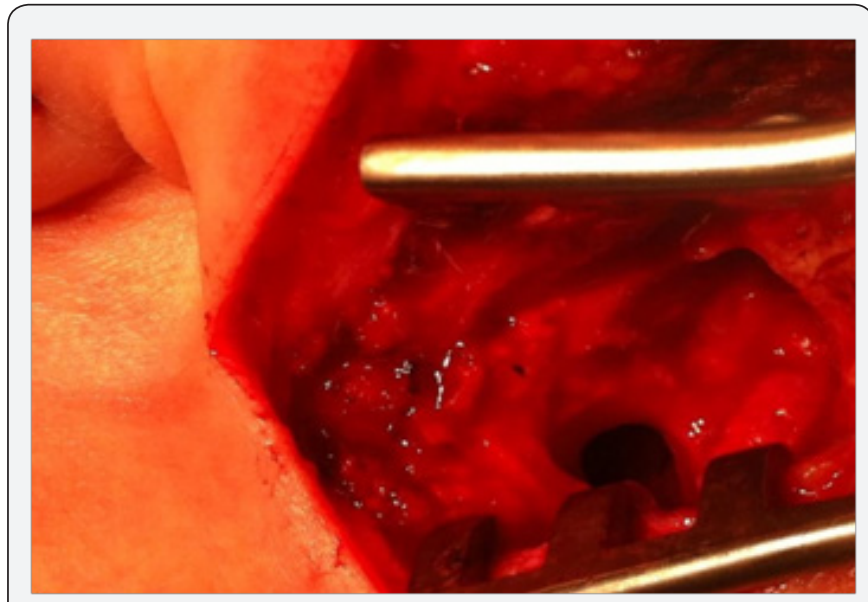

Figure 2: Intraop.pictures-mastoidectomy-the cavity left in place -after removal in block of a solid mass developed in the cavities of the middle, inner ear, mastoid process and temporal bone.

MRI scan-axial: Coronal view, in T1, T2 with gadolinium revealed the complete extension of the process with erosion not in the petrous, mastoid part but also of the squamous part of the temporal, in parietal and occipital bones.The was no cerebral compression or invasion. To obtain a biopsy only with mastoidectomy was possible so using an retro-auricular incision (Figure 2). On the surgery because we want excisional -biopsy we prefer to start as in radical mastoidectomy,under general anaesthesia .Using a posterior approach- retro auricular we explore the cavities a ,mass of pale granulomatous tissue yellowish pink in colour, filled the cavities ,destroyed the horizontal canal wall, invades the middle ear. The malleus, incus and superstructure of the stapes were destroyed by the disease. The facial nerve canal was intact.We remove ,in block the mass leaving in place a large cavity with communication with the cerebellar fossa we remove -erosion of the internal cortical of the mastoid with exposure of the third cranial fossa but without invasion or compression of the nervous tissue. To have acces to this cavity for periodical follow-up and cleaning we create a meatoplasty in the external canal. The histopathological examination of the granulation tissue revealed infiltration with histiocytes associated with eosinophils, lymphocytes, plasma cells and polymorph nuclear giant cells. Immunohistochemical analysis revealed CD68 highlighted numerous macrophages and Langerhans' cells that were also labeled with S100 and CD1a. Immunohistochemical features and morphology were consistent with EG. No complications were noted following the operation and healing of the cavity was normal. After surgery, pure tone air conduction average improved to $20 \mathrm{~dB}$ hearing level, tinnitus and vertigo disappears. Complete body survey to consider metastasis with whole body bone scintigraphy was normal, also follow-up CT evaluation of the temporal bone 1 month postoperatively. Our lady was presented to the department of hematology/oncology for the treatment. -steroids on/m2 body surface also the patient underwent low-dose radiation therapy (10 Gy) .Our patient till now didn't show any sign of recurrence or evolution on every periodically follow -up, not only for the disease but also for the periodical cleaning of the mastoid cavity [6-10].

\section{Introduction}

Eosinophilic granuloma is a rare, benign lesion characterized by uncontrolled proliferation of Langerhans cells. Langerhans cells are differentiated cells of the dendritic cell system and are closely related to the monocyte-macrophage line, normally found in the skin, reticulo-endothelial system, heart, pleura, and lungs. When bones are involved it is usually found at flat and long bones. The most frequent sites of involvement are the skull, spine, ribs, femur, and pelvis. They may be identified by immunehistochemical staining or by the presence of Birbeck granules via electron microscopy.

\section{Langerhans cell histiocytosis (LCH) comprises three different entities: Eosinophilic granuloma, Hand- Schüller-Christian disease, and Letterer-Siwe disease}

Since Hand's article in 1893, several reports appeared it the literature describing proliferative, granulomatous lesions characterized by histiocytes with, giant cells, and the characteristic eosinophils. The term eosinophilic granuloma was first introduced by Lichtenstein and Jaffe in 1940 In 1953, Lichtenstein grouped this spectrum of diseases under the name histiocytosis $\mathrm{X}$. The $-\mathrm{X}$ referred to the fact that the etiology was unknown. In 1987, the term - LCH\| was introduced by the -Writing Group of the Histiocyte Society. Farber in 1941 arrived at the conclusion that eosinophilic granuloma, HandSchuler-Christian disease, and Letterer Siwe disease, represent variations in degree, stage of involvement, and localization of the same basic disease process. It was Lichtenstein[3] who coined the term histiocytosis $\mathrm{X}$, which is used today for this disease. The three variants of histiocytosis $\mathrm{X}$ have related manifestations; but are symp- tomatically and prognostic ally different Letterer Siwe disease is usually a rapidly fatal process occurring most frequently in children below the age of 3 years. The main clinical findings are enlargement of the spleen, liver and lymph nodes; a secondary ane- mia, purpuric coetaneous eruptions, destructive skeletal lesions, especially in the skull, and a downhill febrile course. Hand-Schuler-Christian disease was originally described as a triad syndrome manifested by skull destruction, exophthalmos, and diabetes insipid us. The latter two components are the result of destructive involvement of the sphenoid bone. In present day descriptions, the exophthalmos, and diabetes insipid us need not to occur histopathologically, the primary lesion of LCH is formed by collections of pathologic Langerhans cells with variable numbers of eosinophils, macrophages, and lymphocytes. Diagnostic characteristics of the pathologic Langerhans cells 
include nuclei that appear deeply indented and elongated on light microscopy, cytoplasm that is pale and abundant, Birbeck granules on electron microscopy, expression of CD1 on the cell surface, and positive immunostaining for S100 protein and for the langerin protein [11-15].

Eosinophilic granuloma is the most common form of LCH and accounts for $70 \%$ of the cases of LCH. The etiology and pathogenesis of LCH remain unknown, although more recent research has begun to shed some light on these. Trauma, hereditary pattern, metabolic dysfunction, and viral infections have all been suspected. However, none of them substantiated as yet proliferation of Langerhans cells is monoclonal, so the neoplastic process is possible. An autoimmune mechanism is also proposed. Current thinking favors the notion that $\mathrm{LCH}$ results from immunologic dysfunction that leads to unchecked proliferation of pathologic Langerhans cells. Lichtenstein, consider the disease a pathologic expression of an early, rapidly developing reaction to the etiologic agent, possible a viral infection, because some patients accuse fever and night sweats associated with the appearance of fresh lesions. In eosinophilic granuloma, the lesions begin in the marrow and gradually erode the cortex, the process being localized, most of the cases, but occasionally, the process disseminate. Isolated lesions in the temporal bone are rare, and should be viewed as an early stage of a more diffuse disease process Unifocal eosinophilic granuloma, which occurs in children and young adults, shows a male predominance and appears as a solitary osteolytic lesion in the femora, pelvis, scapulae, vertebrae, ribs, mandible, maxilla, or skull, which includes the temporal bone. The lesion may be asymptomatic, or it may cause pain, local swelling, or pathologic fracture. No systemic manifestations have been reported. The clinical course is typically benign, the prognosis is excellent, and spontaneous regression may occur.

Local curettage with or without low-dose irradiation (approximately $60 \mathrm{~Gy}$ ) 6 is usually curative, although temporary splinting or casting may be necessary for weight-bearing bones. Follow-up examination with a radiographic skeletal survey should be performed to detect lesions at other sites; such lesions are almost always found within 1 year. Eosinophilic granuloma may be best understood as a multifocal form of LCH. It usually occurs in children younger than 5 years of age, and it is characterized by multifocal osteolytic lesions with limited extra skeletal involvement of skin, lymph nodes, and viscera. Multiple lesions are evident at diagnosis or develop within 6 months after a unifocal lesion appears. Systemic manifestations include fever, anorexia, recurrent upper respiratory infections, anterior cervical lymphadenopathy, otitis media, and hepatosplenomegaly. The classic triad

a. osteolytic skull lesions

b. exophthalmos as a result of orbital bone involvement

c. diabetes insipid us secondary to pituitary disease
Chest radiograph may show diffuse pulmonary infiltration, particularly in central and perihilar areas. Hilar lymphadenopathy is rare. Diagnosis requires biopsy of an accessible lesion. Spontaneous regression may occur, but the disease is typically chronic, and low-dose chemotherapy may be required to control systemic manifestations.

\section{Otologic Manifestations}

The mastoid is a common site of involvement in LCH. When small, the lesion is asymptomatic. As it expands, it

\section{May Manifest in Several Ways:}

a) By erosion of the posterior bony canal wall;

b) By erosion through the cortex of the mastoid, zygomatic, or squamous portions; or

c) By secondary infection.

\section{The otic capsule and facial nerve are relatively} resistant:
b) Vertigo,
e) Otorrhea,
f) Post auricular swelling,
g) hearing loss,
h) Vertigo.

a) Sensor neural hearing loss (SNHL)

c) Facial nerve paralysis can occur, but infrequent.

d) Extension beyond the temporal bone to the jugular fossa and skull base is rare. The most common symptom

\section{The most common sign}

a. Granulation tissue or aural polyps in the external auditory canal.

b. Perforation of the tympanic membrane,

c. Otitis media

d. Otitis externa

e. Fistula between the mastoid and the external canal

f. Nontender post auricular swelling.

g. Inner ear symptoms and a positive fistula test are found in the presence of an intact tympanic membrane.

The disease often mimics chronic otitis media, and mastoid surgery is frequently performed before the diagnosis is made.

\section{Diagnosis of LCH is suggested by}

a) An inflammatory disorder of the middle ear and mastoid that does not respond to routine antibiotic therapy,

b) Bilateral destructive ear disease, 
c) An elevated erythrocyte sedimentation rate (esr) in the absence of acute infection,

d) Exuberant granulation tissue after mastoid surgery with a persistently draining cavity, and

e) Associated skin and systemic lesions.

Differential diagnosis of eosinophilic granuloma includes

Suppurative otitis/mastoiditis, cholesteatoma,

a) External otitis,

b) Glomus tympanicum

c) Cancer of the eac or middle ear or regional invading the ear-parotid

d) Primary bone tumors

e) Metastatic tumors.

\section{Diagnosis}

Laboratory and radiologic evaluation must serve to rule out infectious or metabolic processes, neoplastic diseases, and cholesteatoma. If eosinophilic granuloma i possibility of systemic involvement or multiple bony lesions should be considered. For this reason, the investigation should include

\section{Lab Test}
a) $\mathrm{CBC}$ - hematologic evaluation
b) ESR - erythrocyte sedimentation rate
c) Lliver function tests, urinalysis

\section{Imagistics}

a) $\mathrm{Rx}$ profile skull or Schuler view can reveal areas of osteitis.

b) CT scan better defines the extension of the granulomatous mass in relationship to the central nervous system and extra temporal sites.

c) MRI helps in the better demarcation of the soft tissues and relationship of the tumor to the dura with the possibility of infiltration.
d) Chest X-ray.
e) Bone scintigraphy.
f) PET-CT for metastatic series.

\section{The histopathological Diagnosis:}

Eosinoplilic granuloma (EG) is established on the basis of morphologic, immunochemical, and ultra structural features. Grossly, the tumor mass is fragile and faintly yellow to reddishbrown and may contain areas of necrosis or hemorrhage. Microscopically, numerous large round histiocytes with rounded, often indented, nuclei are surrounded by variable numbers of eosinophils with occasional neutrophils, lymphocytes, and plasma cells. Multinucleated giant cells are usually present.

\section{Immunochemical Staining}

Usually provides a positive diagnosis with CD1 antigen, S100 protein, ATPase, alfa-D-mannosidase, and peanut lectin. Cytoplasmic organelles, termed Birbeck granules, are highly specific in Langerhans' cell but can only be seen by electron microscopy.

\section{Treatment}

Depends on the extent of disease at the time of diagnosis. Single lesions can be successfully treated with either surgery or radiotherapy alone, local injections of steroids, avoiding radiation in children. Spontaneous remission is also reported. For multisystem disease, besides surgery and local radiotherapy, chemotherapy may be required. In our case, we performed radical mastoid surgery. Low-dose radiation therapy (10-20 Gy) was added due to close proximity of tumor to the dura. The prognosis is self-limiting and excellent in the absence of no osseous involvement or multifocal process. Long-term follow-up is recommended for early detection of recurrence or progression of the disease to new bony lesions or systemic involvement. Prognosis Adverse prognostic factors are young age and multiorgan involvement and organ dysfunction. Bilateral simultaneous involvement is very rare [16-20].

\section{Conclusion}

a) Eosinophilic granuloma is the most benign form of Histiocitosis X.

b) Temporal bone it is a frequent place but other bones can be involved, or it's just part of a more extended disease.

c) A complete examination, lab tests, imagistics, scintigraphy are necessary to exclude multifocal or disseminated forms of LCH.

d) Early detection and multidisciplinary approach are imperative to plan the best management strategy for the best possible outcome of the disease

e) Clinically, it may present as otorrhea, otalgia, hearing loss, vertigo,tinnitus facial palsy, retroauricular swelling or manifest itself bilaterally.

f) It may be mistaken for a cholesteatoma, Bell palsy or a tuberculous mastoiditis., tumor of the temporal bone in our case with Meniere disease but also as a TMJ disorder.

g) If presents with a polypoidal mass in the EAC- can be confuse with a otomastoiditis,tumors like glomus tympani, carcinoma

h) Although X-rays may indicate the nature of the lesion by showing punched out osteolytic areas, the final diagnosis is histopathological. 
i) Surgery with radiotherapy gives very good results. Radiotherapy alone is also seen to cause regression of the disease intra-lesion injection with steroids instead of radiation are controversial.

j) Spontaneous regression is possible

k) Chemotherapy is important in disseminated forms.

l) Long follow-up is important to prevent recurrence.

\section{References}

1. Bayazit Y, Sirikci A, Bayaram M, Kanlikama M, Demir A, et al. (2001) Eosinophilic granuloma of the temporal bone. Auris Nasus Larynx 28: 99-102.

2. Hernandez-Juyol M, Boj-Quesada JR, Gallego, Melcon S (2003) Oral manifestations of Langerhans cell histiocytosis. Case study of a twoyear-old boy. Med Oral Patol Oral Cir Bucal 8(1):19-25.

3. Pekiner FN, Borahan MO, Ozbayrak S, Alatlı C, Kizılyel G (2012) Oral manifestations of chronic disseminated langerhans cell histiocytosis: a case report MUSBED 2: 138-42.

4. Boston M, Derkay CS (2002) Langerhans' cell histiocytosis of the temporal boneand skull base. Am J Otolaryngology 23: 246-248.

5. David R, Oria RA, Kumar R, Singleton EB, Lindell MM, et al. (1989) Radiologic features of eosinophilic granuloma of bone. Am JRoentgenol 153: 1021-1026.

6. Cline MJ, Golde DW (1973) A review and reevaluation of the histolytic disorders. Am J Med 55: 49-60.

7. Appling D, Jenkins HA, Patton GA (1983) Eosinophilic granuloma in the temporalbone and skull. Otolaryngol Head Neck Surg 91:358-365.

8. Cunningham MJ, Curtin HD, Butkiewicz BL (1988) Histiocytosis X of the temporal bone: CT findings. J Comput Assist Tomogr 12: 70-74.
9. Lichtenstein L (1953) Histiocytosis X; Integration of eosinophilic granuloma of bone, Letterer-Siwe disease, and Schüller-Christian disease as related manifestations of a single nosologic entity. AMA Arch Pathol 56: 84-102.

10. Chu T, D’Angio GJ, Favara BE, Ladisch S, Nesbit M, et al. (1987) Histiocytosis syndromes in children. Lancet 2: 41-42.

11. Lee YS, Kwon JT, Park YS (2008) Eosinophilic granuloma presenting as an epidural hematoma and cyst. J Korean Neurosurg Soc 43(6): 304306.

12. Rao PB (1965) A case record of eosincphilic granuloma and its pathology. J Laryngol and Otol 79: 62-65.

13. Schuknecht HF, Perlman HB(1948) Hand-Schuller-Christian Disease and eosinophilic granuloma of the skull. Ann Otol Rhinol and Laryngol 57: 643- 676.

14. Schwartzman JA, Pulec JL, Linthicum FH (1972) Uncommon granulomatous diseases of the ear. Ann Otol Rhinol \& Laryngol 81: 389393.

15. Straka JA, Caparosa RJ (1972) Eosinophilic granuloma of the temporal bone. Laryngoscope 82: 41-43.

16. Tos M (1963) ENT manifestations in Letters-Siwe's Disease. Acta Otolaryngol 56: 84-92.

17. Badalian-Very G, Vergilio JA, Fleming M (2013) Pathogenesis of Langerhans cell histiocytosis. Annu Rev Pathol 24(8): 1-20.

18. DiCaprio MR, Roberts TT (2014) Diagnosis and Management of LangerhansCell Histiocytosis. J Am Acad Orthop Surg 22(10): 643-652.

19. Abdel-Aziz M, Rashed M, Khalifa B (2014) et al. Eosinophilic granuloma of the temporal bone in children. J Craniofac Surg 25(3): 1076-1078

20. Nanduri VR, Pritchard J, Chong WK, Phelps PD, Sirimanna K, et al (1998). Labyrinthine involvement in Langerhans' cell histiocytosis. Int J Pediatr Otorhinolaryngol 46(1-2): 109-15.

\section{Your next submission with Juniper Publishers will reach you the below assets}

- Quality Editorial service

- Swift Peer Review

- Reprints availability

- E-prints Service

- Manuscript Podcast for convenient understanding

- Global attainment for your research

- Manuscript accessibility in different formats

( Pdf, E-pub, Full Text, Audio)

- Unceasing customer service

Track the below URL for one-step submission https://juniperpublishers.com/online-submission.php 